\title{
Influence of initiation time and white blood cell count on the efficacy of cytotoxic agents in acute promyelocytic leukemia during induction treatment
}

\author{
FANG XU ${ }^{1}$, CHANG-XIN YIN ${ }^{2}$, CHUN-LI WANG $^{2}$, BING-JIE DING $^{2}$, QING-XIU ZHONG ${ }^{3}$, \\ XUE-JIE JIANG ${ }^{2}$, LING JIANG ${ }^{2}$, ZHI-XIANG WANG ${ }^{2}$ and FAN-YI MENG ${ }^{2,3}$ \\ ${ }^{1}$ Hematology Department, Mianyang Central Hospital, Mianyang, Sichuan 621000; \\ ${ }^{2}$ Hematology Department, Nanfang Hospital, Southern Medical University, Guangzhou, Guangdong 510515; \\ ${ }^{3}$ Hematology Department, Kanghua Hospital, Dongguan, Guangdong 523080, P.R. China
}

Received July 11, 2017; Accepted May 29, 2018

DOI: $10.3892 /$ br.2018.1120

\begin{abstract}
The present study retrospectively analyzed 96 newly diagnosed acute promyelocytic leukemia (APL) patients with low-intermediate mortality risk to identify the optimum timing to initiate cytotoxic chemotherapy following all-trans retinoic acid (ATRA) administration. Based on white blood cell (WBC) at chemotherapy initiation, the patients were divided into three groups: low WBC (WBC count $\leq 4 \times 10^{9} / 1$ ), intermediate WBC (WBC count $>4 \times 10^{9} / 1$ and $<15 \times 10^{9} / 1$ ) and high $\mathrm{WBC}$ group (WBC count $\geq 15 \times 10^{9} / 1$ ). According to the period from ATRA commencement to chemotherapy, 96 patients were further divided into two groups: $\leq 3$ days group (chemotherapy within 3 days of ATRA) and $>3$ days group (chemotherapy $>3$ days after ATRA). Clinical effects were compared by univariate analysis and multivariate analyses. The incidence rate of differentiation syndrome (DS; also termed retinoic acid syndrome) was 0.0, 11.1 and $40.0 \%$ in the low, intermediate and high WBC groups, respectively $(\mathrm{P}<0.001)$; complete remission $(\mathrm{CR})$ rate was $90.5,100.0$ and $73.3 \%$, respectively $(\mathrm{P}<0.001)$; and the rate of early mortality (defined as fatality during induction treatment) was 4.8, 0.0 and $26.7 \%$, respectively $(\mathrm{P}<0.001)$. No differences were identified in clinicolaboratory parameters between the $\leq 3$ days and $>3$ days groups, except in time to achieve $C R(P=0.004)$
\end{abstract}

Correspondence to: Professor Fan-Yi Meng, Hematology Department, Nanfang Hospital, Southern Medical University, 1838 North Guangzhou Road, Guangzhou, Guangdong 510515, P.R. China

E-mail: mengfu@medmail.com.cn

Abbreviations: APL, acute promyelocytic leukemia; ATRA, all-trans retinoic acid; NCCN, National Comprehensive Cancer Network; WBC, white blood cell; DS, differentiation syndrome; CR, complete remission; ATO, arsenic trioxide; PLT, platelet

Key words: acute promyelocytic leukemia, low-intermediate risk, induction treatment, initiation time, prognosis, chemotherapy and rate of bleeding related to chemotherapy $(\mathrm{P}=0.009)$, both being higher in the $>3$ days group. Multivariate analyses indicated WBC count at chemotherapy was the only independent risk factor for the occurrence of $\mathrm{DS}[\mathrm{P}=0.002$; odds ratio $(\mathrm{OR})=1.058,95 \%$ confidence interval $(\mathrm{CI})=1.021-1.095]$ and early mortality $(\mathrm{P}=0.036$; $\mathrm{OR}=1.036,95 \% \mathrm{CI}=1.002-1.070)$. For newly diagnosed APL patients with low-intermediate risk, chemotherapy initiation should be recommended until WBC count rises to between $4 \times 10^{9} / 1$ and $15 \times 10^{9} / 1$ during induction treatment.

\section{Introduction}

Coagulopathy resulting in critical hemorrhage is a leading cause of early fatality in acute promyelocytic leukemia (APL). The introduction of all-trans retinoic acid (ATRA) and arsenic trioxide (ATO)-based chemotherapy has notably improved clinical outcome for patients with APL, with the disease now considered as a curable malignant pathology $(1,2)$. The National Comprehensive Cancer Network (NCCN) recommends ATRA and anthracycline-based chemotherapy with or without combination with ATO as the standard induction treatment (3). It has been reported that complete remission (CR) rate may reach higher than $80 \%$ and that an early mortality rate (occurring during induction treatment) lower than $10 \%$ can be achieved following this treatment (4-9). However, epidemiological studies based on American and European populations indicated that early mortality of newly diagnosed APL may be underestimated, since a marked number of patients with poor physical status were excluded by the clinical trials or did not survive prior to recruitment (10-12). These findings suggest that initial treatment of APL may not be sufficient to reduce early mortality, and therefore, that induction treatment requires further improvement.

Following use of ATRA, patients may have increased risk of developing leukocytosis and differentiation syndrome (DS) (1). This complication usually occurs during induction therapy, in which leukemic blasts become present in abundance. The syndrome is characterized by unexplained fever, acute respiratory distress and/or capillary 
leak syndrome leading to acute renal failure (13). Therefore, cytotoxic therapeutic agents are required to regulate white blood cells (WBCs). However, considering the possible effects of chemotherapy on coagulation functions, clinicians tend to initiate cytotoxic treatment including anthracycline agents at least 3 days after use of ATRA or until coagulation functions are recovered (2). However, it remains difficult to determine the appropriate time to initiate chemotherapy, and NCCN have not yet provided definitive recommendations. The present study attempted to evaluate the effect of different initiation timings of chemotherapy during induction treatment for APL.

\section{Patients and methods}

Patients. A total of 212 patients with de novo APL were hospitalized at Nanfang Hospital of Southern Medical University (Guangzhou, China) between January 2003 and December 2014. Of these patients, 169 accepted ATRA and cytotoxic agents during induction treatment, among which 96 were categorized into a low-intermediate risk group, and the remaining patients categorized into a high risk group, based on Sanz's risk stratification model for survival prediction (14). All 96 patients [ 47 males and 49 females with a median age of 32 years (range 15-66)] with low-intermediate risk were retrospectively enrolled in the present study. Disease diagnosis was confirmed by bone marrow aspiration, chromosome karyotyping analysis, fluorescence in situ hybridization analysis and polymerase chain reaction tests. Informed consent prior to and regarding the treatment protocol was obtained from all patients analyzed in the present study.

Treatments. When a diagnosis of APL was suspected, ATRA (30 $\mathrm{mg} / \mathrm{m}^{2} /$ day) was administered as early as possible, until CR was achieved. Chemotherapy comprised treatment with idarubicin $\left(8 \mathrm{mg} / \mathrm{m}^{2} /\right.$ day on days 1,3 and 5$)$, daunorubicin (45 mg/m $/ \mathrm{m}^{2}$ day on days 1,3 and 5 ) or homoharringtonine ( $2 \mathrm{mg} / \mathrm{m}^{2} /$ day on days $\left.1-5\right)$; induction treatment was combined with cytarabine $\left(100 \mathrm{mg} / \mathrm{m}^{2} /\right.$ day on days $\left.1-7\right)$ and/or hydroxyurea (2.0-3.0 g/day, adjusted according to regular blood tests). In addition, 36 patients simultaneously received ATO (0.15 mg/kg/day for 14 days). Chemotherapy was applied 0-21 days after initiation of ATRA (median time, 7 days; range, 0-20 days). Blood product support was applied to maintain a platelet (PLT) level $\geq 30 \times 10^{9} / 1$, hemoglobin level $\geq 70 \mathrm{~g} / 1$ and plasma fibrinogen level $\geq 1.5 \mathrm{~g} / 1$. All adverse events related to treatments, including bone marrow depression, infection and bleeding were graded according to the National Cancer Institute Common Terminology Criteria for Adverse Events version 4.03 (15).

Definitions. Retinoic acid syndrome, also known as DS, was diagnosed based on the incidence of at least two of the following clinical features: unexplained fever, acute respiratory distress with interstitial pulmonary infiltrates, acute renal failure, weight gain $>5 \mathrm{~kg}$, unexplained hypotension and pleuropericardial effusion (13). Prevention strategies included dexamethasone (10 $\mathrm{mg} \mathrm{q12h}$ ) and discontinuation of ATRA and ATO. All 96 patients were categorized according to Sanz's risk stratification score (14) as low risk (WBC count $<10.0 \times 10^{9} / 1$ and PLT $\geq 40.0 \times 10^{9} / 1$ at diagnosis) and intermediate risk (WBC count $<10 \times 10^{9} / 1$ and PLT $\left.<40.0 \times 10^{9} / 1\right)$. CR was defined as the presence of $<5 \%$ blast cells in bone marrow aspirates, PLT $>100 \times 10^{9} / 1$ and no juvenile cells in peripheral blood according to the criteria set by the US National Cancer Institute (16). Early mortality was defined as fatality during induction treatment from the first day of hospitalizations. Eastern Cooperative Oncology Group performance status score (0-4 score) was applied to investigate patient's physical status prior to chemotherapy (17).

Groups. In most cases, WBC count increased as ATRA was used. Thresholds were initially set according to the WBC count at chemotherapy initiation as $\leq 4 \times 10^{9} / 1,>4 \times 10^{9}$ and $<10 \times 10^{9} / 1$, and $\geq 10 \times 10^{9} / 1$, since normal WBC count is between $4 \times 10^{9}$ and $10 \times 10^{9} / 1$. However, no significant difference was determined using these classes. The thresholds were therefore altered until it was apparent when use of cytotoxic agents was appropriate. Thus, based on the WBC count at chemotherapy initiation, the 96 patients were divided into three groups: low WBC group (WBC count $\leq 4 \times 10^{9} / 1$ ), intermediate WBC group ( WBC count $>4 \times 10^{9}$ and $<15 \times 10^{9} / 1$ ), high WBC group (WBC count $\geq 15 \times 10^{9} / 1$ ). Table I presents a comparison of the baseline clinical and laboratory parameters of the low, intermediate and high WBC groups. According to the period from ATRA commencement to chemotherapy, the 96 patients were also divided into two groups: $\leq 3$ days group (treated with chemotherapy within 3 days of ATRA) and $>3$ days group (treated with chemotherapy at least 3 days after ATRA). Table II presents a comparison of the baseline clinical and laboratory parameters of these two groups.

Statistical analysis. Statistical analysis was performed with SPSS v.17.0 software (SPSS, Inc., Chicago, IL, USA). All data were collected in January, 2015. Clinical features are presented as percentages (\%) for categorical variables and as mean values \pm standard deviation for normally distributed continuous variables. The $\chi^{2}$ test was used to analyze the significance of differences in the distribution of categorical variables between the patient subsets, and Bonferroni's correction was used post-hoc to compare every two groups. The unpaired Student's test or Mann-Whitney test was used to analyze the significance of differences in the distribution of continuous parametric variables and the distribution of ranked variables. Multivariate analysis was performed by using a binary logistic regression model. WBC count at diagnosis, PLT count at diagnosis, WBC count at chemotherapy initiation and the period from ATRA to chemotherapy were considered in the multivariate analysis to evaluate their effects on DS, early mortality and remission. $\mathrm{P}<0.05$ was considered to indicate a statistically significant difference.

\section{Results}

Comparisons of clinical effects among low, intermediate and high WBC groups. Comparison of the baseline clinical and laboratory parameters showed no notable differences between these groups (Table I). As depicted in Table III, the incidence of DS was $0.0,11.1$ and $40.0 \%$ respectively 
Table I. Baseline demographic, clinical and laboratory characteristics of the low, intermediate and high WBC groups.

\begin{tabular}{|c|c|c|c|c|}
\hline \multirow[b]{2}{*}{ Parameter } & \multicolumn{3}{|c|}{ WBC group } & \multirow[b]{2}{*}{ P-value } \\
\hline & Low & Intermediate & High & \\
\hline Cases & 21 & 45 & 30 & \\
\hline Age, years & $31.6 \pm 10.2$ & $33.8 \pm 10.9$ & $31.8 \pm 12.1$ & 0.542 \\
\hline $15-54$ & $21(100.0)$ & $44(97.8)$ & $28(93.3)$ & \\
\hline $55-70$ & $0(0.0)$ & $1(2.2)$ & $2(6.7)$ & \\
\hline Sex, male/female & $11 / 10$ & $23 / 22$ & $13 / 17$ & 0.755 \\
\hline $\begin{array}{l}\text { WBC count } \\
\text { at diagnosis }\end{array}$ & $1.76 \pm 0.93$ & $1.94 \pm 0.79$ & $6.32 \pm 7.03$ & 0.056 \\
\hline $\begin{array}{l}\text { PLT count } \\
\text { at diagnosis }\end{array}$ & $49.9 \pm 37.7$ & $41.2 \pm 33.7$ & $32.6 \pm 25.9$ & 0.196 \\
\hline \multicolumn{5}{|l|}{$\begin{array}{l}\text { Sanz's risk } \\
\text { stratification }\end{array}$} \\
\hline Low risk & $11(52.4)$ & $16(35.6)$ & $10(33.3)$ & 0.331 \\
\hline Intermediate risk & $10(47.6)$ & $29(64.4)$ & $20(66.7)$ & \\
\hline \multicolumn{5}{|l|}{ ECOG score } \\
\hline $1-2$ & $14(66.7)$ & $23(51.1)$ & $14(46.7)$ & 0.346 \\
\hline $3-4$ & $7(33.3)$ & $22(48.9)$ & $16(53.3)$ & \\
\hline \multicolumn{5}{|l|}{ Induction treatment } \\
\hline $\begin{array}{l}\text { Combined with } \\
\text { arsenic trioxide }\end{array}$ & $9(42.9)$ & $18(40.0)$ & $9(30.0)$ & 0.578 \\
\hline $\begin{array}{l}\text { Combined with } \\
\text { cytarabine }\end{array}$ & $6(28.6)$ & $19(42.2)$ & $15(50.0)$ & 0.310 \\
\hline $\begin{array}{l}\text { Combined with } \\
\text { hydroxyurea }\end{array}$ & $6(28.6)$ & $15(33.3)$ & $20(66.7)$ & 0.006 \\
\hline \multicolumn{5}{|l|}{$\begin{array}{l}\text { Cytotoxic agent } \\
\text { distribution }\end{array}$} \\
\hline Daunorubicin & $6(28.6)$ & $14(31.1)$ & $16(53.3)$ & 0.178 \\
\hline Idarubicin & $11(52.4)$ & $19(42.2)$ & $7(23.3)$ & \\
\hline Homoharringtonine & $4(19.0)$ & $12(26.7)$ & $7(23.3)$ & \\
\hline
\end{tabular}

Values are provided as number of cases $(\%)$ or as the mean \pm standard deviation. WBC, white blood cell; PLT, platelet; ECOG, Eastern Cooperative Oncology Group.

in the low, intermediate and high WBC groups, respectively $(\mathrm{P}<0.001)$. DS incidence was significantly lower in the low and intermediate WBC groups compared with in the high WBC group $(\mathrm{P}=0.001$ and 0.003$)$. There was no difference in the extent of bone marrow suppression between the three groups. Grade 3-4 infection rates were 71.4, 33.3 and $43.3 \%(\mathrm{P}=0.015)$. Multiple comparisons indicated grade 3-4 infection in the low WBC group was significantly more prevalent than that in the intermediate WBC group $(\mathrm{P}=0.004)$. Grade 3-4 bleeding rates were 9.5, 26.7 and $40.0 \%$, respectively $(\mathrm{P}=0.055)$, which in the low $\mathrm{WBC}$ group was significantly lower than in the high WBC group $(\mathrm{P}=0.016)$. CR rates were $90.5,100$ and $73.3 \%$, respectively $(\mathrm{P}<0.001)$, which of the intermediate WBC group was significantly higher than of the high WBC group $(\mathrm{P}=0.001)$. Early mortality rate in each group was $4.8,0.0$ and $26.7 \%$, respectively $(\mathrm{P}<0.001)$, and determined as significantly
Table II. Baseline demographic, clinical and laboratory characteristics of the $\leq 3$ and $>3$ days interval groups.

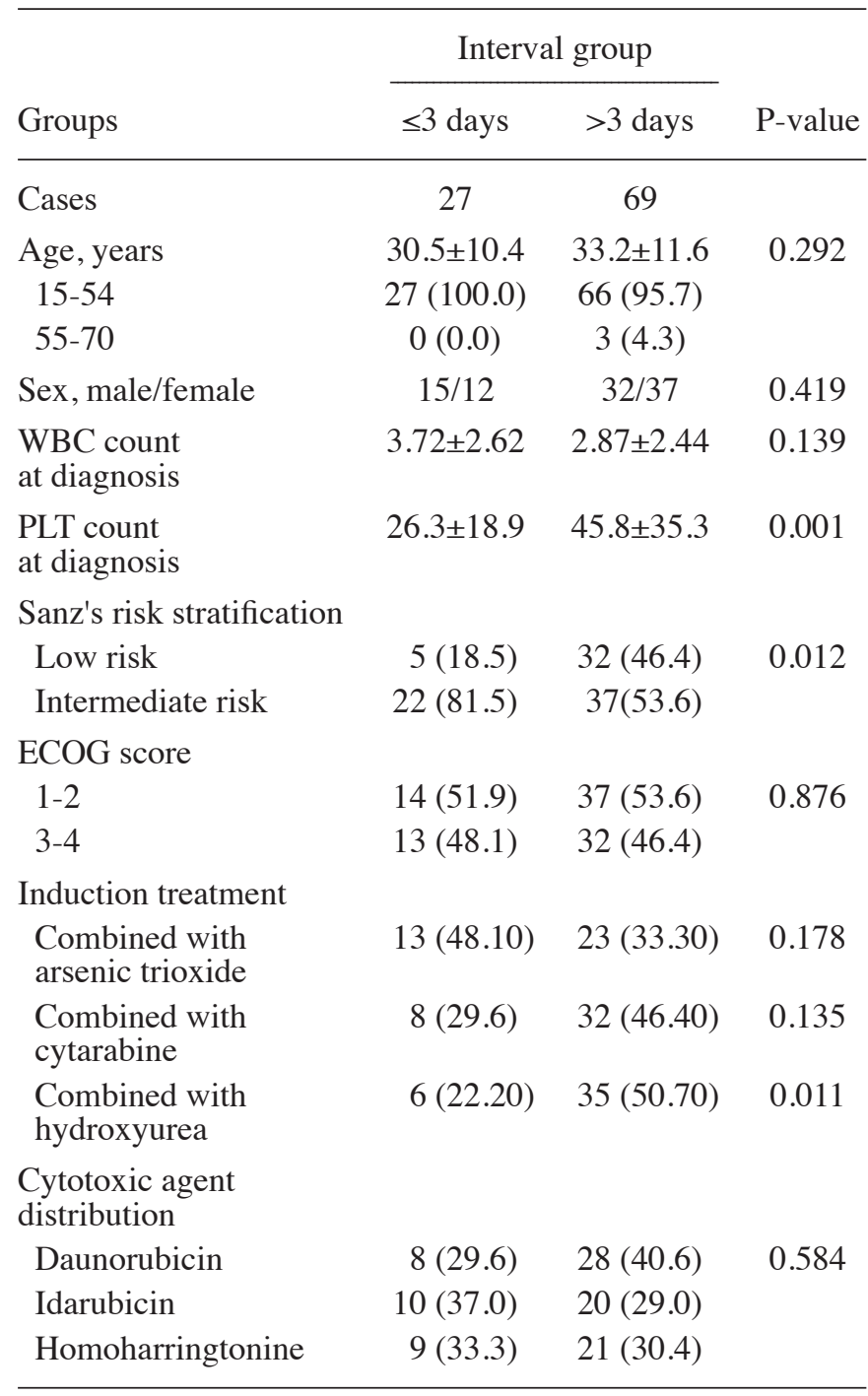

Values are provided as number of cases $(\%)$ or as the mean \pm standard deviation. WBC, white blood cell; PLT, platelet; ECOG, Eastern Cooperative Oncology Group.

higher in the high WBC group than in the intermediate WBC group $(\mathrm{P}=0.003)$. The time to achieve $\mathrm{CR}$ was similar between the three groups $(\mathrm{P}=0.498$; Table III).

Comparisons of clinical effects between the $\leq 3$ days and $>3$ days groups. Comparison of the baseline clinical and laboratory parameters revealed that PLT count was higher in the $>3$ days group $(\mathrm{P}=0.001)$. Time between ATRA and chemotherapy was also associated with the distribution of Sanz's risk stratification ( $\mathrm{P}=0.012$; Table II). Regarding the initiation time of chemotherapy, there were no significant differences in DS incidence, grade 3-4 bone marrow suppression rate, grade 3-4 infection rate, $\mathrm{CR}$ rate and early mortality rate between the $\leq 3$ days and $>3$ days groups (Table IV). Time to achieve $\mathrm{CR}$ was longer in the $>3$ days group $(37.6 \pm 10.0$ vs. $30.8 \pm 11.7$ days; $P=0.004)$. Although PLT count was higher in the $>3$ days group, bleeding related to chemotherapy was also more prevalent in the $>3$ days group 
Table III. Comparisons of clinical effects in the low, intermediate and high WBC groups.

\begin{tabular}{|c|c|c|c|c|}
\hline \multirow[b]{2}{*}{ Parameter } & \multicolumn{3}{|c|}{ WBC group } & \multirow[b]{2}{*}{ P-value } \\
\hline & Low & Intermediate & High & \\
\hline Cases & 21 & 45 & 30 & \\
\hline DS incidence & $0(0.0)^{\mathrm{a}}$ & $5(11.1)^{b}$ & $12(40.0)$ & $<0.001$ \\
\hline $\begin{array}{l}\text { Grade } 3-4 \text { bone } \\
\text { marrow depression }\end{array}$ & $20(95.2)$ & $42(93.3)$ & $23(82.1)$ & $0.047^{\mathrm{g}}$ \\
\hline $\begin{array}{l}\text { Grade } 3-4 \\
\text { infection }\end{array}$ & $15(71.4)^{\mathrm{c}}$ & $15(33.3)$ & $13(43.3)$ & 0.015 \\
\hline $\begin{array}{l}\text { Bleeding related } \\
\text { to chemotherapy }\end{array}$ & $2(9.5)^{d}$ & $12(26.7)$ & $12(40.0)$ & 0.055 \\
\hline $\begin{array}{l}\text { Lowest WBC } \\
\text { count } \times 10^{9} / 1\end{array}$ & $0.78 \pm 9.18$ & $1.21 \pm 0.70$ & $1.07 \pm 0.57$ & 0.033 \\
\hline $\begin{array}{l}\text { Highest WBC } \\
\text { count } \times 10^{9} / 1\end{array}$ & $9.02 \pm 9.18$ & $14.91 \pm 9.98$ & $39.24 \pm 24.45$ & $<0.001$ \\
\hline $\mathrm{CR}$ rate & $19(90.5)$ & $45(100.0)^{\mathrm{e}}$ & $22(73.3)$ & $<0.001$ \\
\hline $\begin{array}{l}\text { Time to } \\
\text { achieve CR, days }\end{array}$ & $34.8 \pm 15.6$ & $35.1 \pm 10.3$ & $31.6 \pm 8.8$ & 0.498 \\
\hline Early mortality rate & $1(4.8)$ & $0(0.0)^{\mathrm{f}}$ & $8(26.7)$ & $<0.001$ \\
\hline Mortality cause & & & & 0.704 \\
\hline Hemorrhage & 1 & 0 & 3 & \\
\hline DS & 0 & 0 & 2 & \\
\hline Infection & 0 & 0 & 1 & \\
\hline Other & 0 & 0 & 2 & \\
\hline
\end{tabular}

Values are provided as number of cases $(\%)$ or as the mean \pm standard deviation. ${ }^{\mathrm{a}} \mathrm{P}=0.001$ vs. high $\mathrm{WBC}$ group; ${ }^{\mathrm{b}} \mathrm{P}=0.003$ vs. high $\mathrm{WBC}$ group; ${ }^{\mathrm{C}} \mathrm{P}=0.004$ vs. intermediate $\mathrm{WBC}$ group; ${ }^{\mathrm{d}} \mathrm{P}=0.016$ vs. high $\mathrm{WBC}$ group; ${ }^{\mathrm{e}} \mathrm{P}=0.001$ vs. high $\mathrm{WBC}$ group; ${ }^{\mathrm{f}} \mathrm{P}=0.003$ vs. high $\mathrm{WBC}$ group. WBC, white blood cell; DS, differentiation syndrome; CR, complete

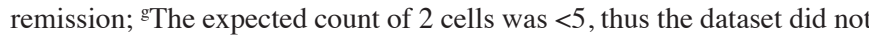
satisfy requirements of $\chi^{2}$ test and the P-value is not significant.

(33.3 vs. 7.4\%, $\mathrm{P}=0.009$; Table IV). To eliminate the effect of PLT count, multivariate analysis was performed to correct for bias.

Multivariate associations. The results of multivariate analysis revealed that WBC count at chemotherapy initiation was an independent risk factor for the occurrence of DS $[\mathrm{P}=0.002$, odds ratio $(\mathrm{OR})=1.058,95 \%$ confidence interval (CI) $=1.021-1.095]$. WBC count at chemotherapy initiation was also indicated to influence the occurrence of early mortality $(\mathrm{P}=0.036, \mathrm{OR}=1.036,95 \% \mathrm{CI}=1.002-1.070)$. However, the period from ATRA to chemotherapy, WBC count at diagnosis and PLT count at diagnosis were not independent risk factors for DS, early mortality or remission failure (Table V).

\section{Discussion}

NCCN guidelines recommend anthracycline-based chemotherapy as one part of induction treatment for newly diagnosed APL in order to reduce WBC count (3). However, the guidelines do not specify when to initiate chemotherapy. Tallman and Altman (2) suggested that chemotherapy should
Table IV. Comparison of clinical effects in the $\leq 3$ and $>3$ days interval groups.

\begin{tabular}{|c|c|c|c|}
\hline \multirow[b]{2}{*}{ Parameter } & \multicolumn{2}{|c|}{ Interval group } & \multirow[b]{2}{*}{ P-value } \\
\hline & $\leq 3$ days & $>3$ days & \\
\hline Cases & 27 & 69 & \\
\hline DS incidence & $4(14.8)$ & $13(18.8)$ & 0.867 \\
\hline $\begin{array}{l}\text { Grade } 3-4 \text { bone } \\
\text { marrow depression }\end{array}$ & $23(88.5)$ & $62(91.2)$ & 0.993 \\
\hline Grade 3-4 infection & $12(44.4)$ & $31(44.9)$ & 0.966 \\
\hline $\begin{array}{l}\text { Bleeding related } \\
\text { to chemotherapy }\end{array}$ & $2(7.4)$ & $23(33.3)$ & 0.009 \\
\hline $\begin{array}{l}\text { Lowest WBC } \\
\text { count } \times 10^{9} / 1\end{array}$ & $1.16 \pm 0.69$ & $1.05 \pm 0.61$ & 0.435 \\
\hline $\begin{array}{l}\text { Highest WBC } \\
\text { count } \times 10^{9} / 1\end{array}$ & $18.4 \pm 12.0$ & $22.8 \pm 22.5$ & 0.347 \\
\hline $\mathrm{CR}$ rate & $24(88.9)$ & $62(89.9)$ & 1.000 \\
\hline $\begin{array}{l}\text { Time to } \\
\text { achieve CR, days }\end{array}$ & $30.8 \pm 11.6$ & $37.6 \pm 10.0$ & 0.004 \\
\hline Early mortality rate & $3(11.1)$ & $6(8.7)$ & 1.000 \\
\hline \multicolumn{4}{|l|}{ Mortality cause } \\
\hline Hemorrhage & 1 & 3 & 0.771 \\
\hline DS & 1 & 1 & \\
\hline Infection & 0 & 1 & \\
\hline Other & 1 & 1 & \\
\hline
\end{tabular}

Values are provided as number of cases $(\%)$ or as the mean \pm standard deviation. WBC, white blood cell; DS, differentiation syndrome; $\mathrm{CR}$, complete remission.

be used at least 1-3 days after ATRA and in newly diagnosed, low-intermediate-risk APL with $\mathrm{WBC}>5 \times 10^{9} / 1$. To the best of our knowledge, there is a lack of studies on the optimal timing of chemotherapy during induction treatment. Therefore, this was a focus of the present study, investigated through univariate and multivariate analyses.

de Botton et al (18) reported that early addition of chemotherapy to ATRA therapy in newly diagnosed cases of APL with low WBC counts significantly reduced the incidence of ATRA syndrome (9.2\%), compared with in those who received chemotherapy until CR was achieved (18.0\%). Furthermore, the incidence of early mortality related to DS was lower ( 0.5 vs. $2.5 \%)$. In the present study, DS incidence was $17.7 \%$, similar to that reported by de Botton et al, but $>24.8 \%$ reported for clinical trials LPA96 and LPA99 $(18,19)$. Inconsistent diagnostic criteria for DS may account for the differences. In the study by de Botton et al, DS diagnosis was established on the basis of satisfying at least three clinical signs. In the present study, and LPA96 and LPA99, DS diagnosis was made on the basis of satisfying at least two clinical signs. However, de Botton et al investigated newly diagnosed APL with low or intermediate risk, as in the present study; whereas LPA96 and LPA99 did not stratify the patients included in the clinical trials. Furthermore, de Botton et al focused on the effect of chemotherapy used in different periods on DS incidence. 
Table V. Multivariate analysis of WBC count at chemotherapy, the period from ATRA to chemotherapy, and WBC and PLT counts at diagnosis.

\begin{tabular}{|c|c|c|c|c|c|c|c|}
\hline $\begin{array}{l}\text { Dependent } \\
\text { variable }\end{array}$ & $\begin{array}{l}\text { Independent } \\
\text { variables }\end{array}$ & $\mathrm{B}$ & $\begin{array}{l}\text { Standard } \\
\text { error }\end{array}$ & $\begin{array}{c}\text { Wald } \\
\text { coefficient }\end{array}$ & P-value & Odds ratio & $95 \%$ confidence interval \\
\hline \multirow[t]{4}{*}{$\begin{array}{l}\text { Differentiation } \\
\text { syndrome }\end{array}$} & $\begin{array}{l}\text { WBC count } \\
\text { on chemotherapy }\end{array}$ & 0.056 & 0.018 & 9.918 & 0.002 & 1.058 & $1.021-1.095$ \\
\hline & $\begin{array}{l}\text { Period from ATRA } \\
\text { to chemotherapy }\end{array}$ & 0.003 & 0.044 & 0.006 & 0.964 & 1.003 & $0.921-1.093$ \\
\hline & WBC count at diagnosis & 0.164 & 0.107 & 2.342 & 0.111 & 1.179 & $0.955-1.455$ \\
\hline & PLT count at diagnosis & -0.001 & 0.011 & 0.011 & 0.796 & 0.999 & $0.978-1.020$ \\
\hline \multirow[t]{4}{*}{$\begin{array}{l}\text { Early } \\
\text { mortality }\end{array}$} & $\begin{array}{l}\text { WBC count } \\
\text { on chemotherapy }\end{array}$ & 0.035 & 0.017 & 4.391 & 0.036 & 1.036 & $1.002-1.070$ \\
\hline & $\begin{array}{l}\text { Period from ATRA } \\
\text { to chemotherapy }\end{array}$ & -0.010 & 0.063 & 0.024 & 0.519 & 0.990 & $0.876-1.120$ \\
\hline & WBC count at diagnosis & 0.140 & 0.133 & 1.109 & 0.217 & 1.150 & $0.887-1.491$ \\
\hline & PLT count at diagnosis & -0.021 & 0.019 & 1.202 & 0.200 & 0.979 & 0.943-1.017 \\
\hline \multirow[t]{4}{*}{$\begin{array}{l}\text { Remission } \\
\text { failure }\end{array}$} & $\begin{array}{l}\text { WBC count } \\
\text { on chemotherapy }\end{array}$ & 0.031 & 0.019 & 2.616 & 0.106 & 1.032 & $0.993-1.071$ \\
\hline & $\begin{array}{l}\text { Period from ATRA } \\
\text { to chemotherapy }\end{array}$ & 0.039 & 0.053 & 0.559 & 0.455 & 1.040 & $0.938-1.153$ \\
\hline & WBC count at diagnosis & 0.130 & 0.128 & 1.036 & 0.309 & 1.139 & $0.887-1.463$ \\
\hline & PLT count at diagnosis & -0.024 & 0.018 & 1.799 & 0.180 & 0.976 & $0.942-1.011$ \\
\hline
\end{tabular}

WBC, white blood cell; ATRA, all-trans retinoic acid; PLT, platelet.

The present study also assessed other factors related to early mortality, including infection, bleeding and $\mathrm{CR}$ rate, among others, which may be influenced by the initiation time of chemotherapy.

Following the use of ATRA, WBC count typically rises gradually, and risk associated with DS increases (13). Initiation of chemotherapy at different intervals during induction treatment for APL may lead to different outcomes. The present study demonstrated that when chemotherapy was initiated at a WBC count $<4 \times 10^{9} / 1$ and $>15 \times 10^{9} / 1$, the patients exhibited higher CR rate (100.0\%), lower early mortality rate $(0.0 \%)$ and reduced possibility of infection $(33.3 \%)$. For those who received chemotherapy at a WBC count $<4 \times 10^{9} / 1$, infection rate was the most notable issue (71.4\%) despite the lower incidence of DS $(5.9 \%)$. As for the patients treated with chemotherapy at a WBC count $\geq 5 \times 10^{9} / 1$, DS incidence, bleeding rate, early mortality, $\mathrm{CR}$ rate and time to $\mathrm{CR}$ all appeared worse compared with the other two groups. These results may have been due to the following reasons: firstly, once the patients were treated with chemotherapy when WBC counts rose $\geq 15 \times 10^{9} / 1$, both the risk of DS and early mortality associated with DS may have increased markedly. Secondly, if WBC counts were too low, particularly if resulting in neutropenia, when chemotherapy was applied, infection may have been a main cause of increased early mortality rate. Therefore, the present study suggests treatment of newly diagnosed APL with chemotherapy when WBC count is between $4 \times 10^{9}$ and $15 \times 10^{9} / 1$. However, for those whose WBC counts are consistently low, whether chemotherapy is needed is worthy of further investigation. It is generally viewed that coagulant function may be improved at least 3 days after the initiation of ATRA $(2,20)$. However, in terms of the period from ATRA commencement to chemotherapy, the patients treated with chemotherapy within 3 days of ATRA did not exhibit differences from those treated at least 3 days after with regards to early mortality rate, DS incidence and CR rate.

Due to the retrospective nature of the present study, to decrease selection bias, the study aimed to confirm risk factors by multivariate analyses. The effects of WBC count at diagnosis, PLT count at diagnosis, WBC count at chemotherapy initiation and the period from ATRA commencement to chemotherapy were considered. The results indicated WBC count at chemotherapy was the only index capable of influencing the incidence of DS and early mortality. With regard to ethics, it is difficult to design a prospective randomized controlled trial to evaluate the appropriate time to use cytotoxic agents. However, a single-arm prospective trial may be considered for comparison with historical data.

Overall, for newly diagnosed APL with low-intermediate risk, patients may benefit more when chemotherapy is initiated at a WBC count between $4 \times 10^{9} / 1$ and $15 \times 10^{9} / 1$ during induction treatment.

\section{Acknowledgements}

The present study used the electronic medical record database of Nanfang Hospital, Southern Medical University (Guangzhou, China).

\section{Funding}

Not applicable. 


\section{Availability of data and materials}

The datasets used and/or analyzed during the present study are available from the corresponding author on reasonable request.

\section{Authors' contributions}

FX and FYM conceived the study and analyzed and interpreted the data. FX wrote the draft manuscript and performed the statistical analyses. CXY, CLW, BJD, QXZ, XJJ, LJ and ZXW collected patient data, reviewed the manuscript, and revised it critically for intellectual content. All authors read and approved the final study to be published.

\section{Ethics approval and consent to participate}

Ethical approval was not obtained for the present study due to its retrospective nature. Informed consent prior to and regarding the treatment protocol was obtained from all patients analyzed in the present study.

\section{Patient consent for publication}

Informed consent for publication was obtained from all patients analyzed in the present study.

\section{Competing interests}

The authors declare that they have no competing interests.

\section{References}

1. Lo-Coco F, Avvisati G, Vignetti M, Thiede C, Orlando SM, Iacobelli S, Ferrara F, Fazi P, Cicconi L, Di Bona E, et al; Gruppo Italiano Malattie Ematologiche dell'Adulto; German-Austrian Acute Myeloid Leukemia Study Group; Study Alliance Leukemia: Retinoic acid and arsenic trioxide for acute promyelocytic leukemia. N Engl J Med 369: 111-121, 2013.

2. Tallman MS and Altman JK: How I treat acute promyelocytic leukemia. Blood 114: 5126-5135, 2009.

3. O'Donnell MR, Tallman MS, Abboud CN, Altman JK, Appelbaum FR, Arber DA, Attar E, Borate U, Coutre SE, Damon LE, et al; National Comprehensive Cancer Network: Acute myeloid leukemia, version 2.2013. J Natl Compr Canc Netw 11: 1047-1055, 2013.

4. Mandelli F, Diverio D, Avvisati G, Luciano A, Barbui T, Bernasconi C, Broccia G, Cerri R, Falda M, Fioritoni G, et al: Molecular remission in PML/RAR alpha-positive acute promyelocytic leukemia by combined all-trans retinoic acid and idarubicin (AIDA) therapy. Gruppo Italiano-Malattie Ematologiche Maligne dell'Adulto and Associazione Italiana di Ematologia ed Oncologia Pediatrica Cooperative Groups. Blood 90: 1014-1021, 1997.

5. Rodeghiero F, Avvisati G, Castaman G, Barbui T and Mandelli F: Early deaths and anti-hemorrhagic treatments in acute promyelocytic leukemia. A GIMEMA retrospective study in 268 consecutive patients. Blood 75: 2112-2117, 1990.

6. Miller WH Jr, Kakizuka A, Frankel SR, Warrell RP Jr, DeBlasio A, Levine K, Evans RM and Dmitrovsky E: Reverse transcription polymerase chain reaction for the rearranged retinoic acid receptor alpha clarifies diagnosis and detects minimal residual disease in acute promyelocytic leukemia. Proc Natl Acad Sci USA 89: 2694-2698, 1992.
7. Hu J, Liu YF, Wu CF, Xu F, Shen ZX, Zhu YM, Li JM, Tang W, Zhao WL, Wu W, et al: Long-term efficacy and safety of all-trans retinoic acid/arsenic trioxide-based therapy in newly diagnosed acute promyelocytic leukemia. Proc Natl Acad Sci USA 106: 3342-3347, 2009.

8. Yanada M, Matsushita T, Asou N, Kishimoto Y, Tsuzuki M, Maeda Y, Horikawa K, Okada M, Ohtake S, Yagasaki F, et al: Severe hemorrhagic complications during remission induction therapy for acute promyelocy tic leukemia: Incidence, risk factors, and influence on outcome. Eur J Haematol 78: 213-219, 2007.

9. Iland H, Bradstock K, Seymour J, Hertzberg M, Grigg A Taylor K, Catalano J, Cannell P, Horvath N, Deveridge S, et al; Australasian Leukaemia and Lymphoma Group: Results of the APML3 trial incorporating all-trans-retinoic acid and idarubicin in both induction and consolidation as initial therapy for patients with acute promyelocytic leukemia. Haematologica 97: 227-234, 2012.

10. Park JH, Qiao B, Panageas KS, Schymura MJ, Jurcic JG, Rosenblat TL, Altman JK, Douer D, Rowe JM and Tallman MS: Early death rate in acute promyelocytic leukemia remains high despite all-trans retinoic acid. Blood 118: 1248-1254, 2011.

11. Chen Y, Kantarjian H, Wang H, Cortes J and Ravandi F: Acute promyelocytic leukemia: A population-based study on incidence and survival in the United States, 1975-2008. Cancer 118: 5811-5818, 2012.

12. Lehmann S, Ravn A, Carlsson L, Antunovic P, Deneberg S, Möllgård L, Derolf AR, Stockelberg D, Tidefelt U, Wahlin A, et al: Continuing high early death rate in acute promyelocytic leukemia: A population-based report from the Swedish Adult Acute Leukemia Registry. Leukemia 25: 1128-1134, 2011.

13. Frankel SR, Eardley A, Lauwers G, Weiss M and Warrell RP: The 'retinoic acid syndrome' in acute promyelocytic leukemia. Ann Intern Med 117: 292-296, 1992.

14. Sanz MA, Lo Coco F, Martín G, Avvisati G, Rayón C, Barbui T, Díaz-Mediavilla J, Fioritoni G, González JD, Liso V, et al: Definition of relapse risk and role of nonanthracycline drugs for consolidation in patients with acute promyelocytic leukemia: A joint study of the PETHEMA and GIMEMA cooperative groups. Blood 96: 1247-1253, 2000.

15. National Cancer Institute: Common Terminology Criteria for Adverse Events. Version 4.03. https://www.eortc.be/services/ doc/ctc/CTCAE_4.03_2010-06-14_QuickReference_5x7.pdf. Accessed June $1 \overline{4}, 2010$.

16. Cheson BD, Bennett JM, Kopecky KJ, Büchner T, Willman CL, Estey EH, Schiffer CA, Doehner H, Tallman MS, Lister TA, et al; International Working Group for Diagnosis, Standardization of Response Criteria, Treatment Outcomes, and Reporting Standards for Therapeutic Trials in Acute Myeloid Leukemia: Revised recommendations of the international working group for diagnosis, standardization of response criteria, treatment outcomes, and reporting standards for therapeutic trials in acute myeloid leukemia. J Clin Oncol 21: 4642-4649, 2003.

17. Oken MM, Creech RH, Tormey DC, Horton J, Davis TE, McFadden ET and Carbone PP: Toxicity and response criteria of the Eastern Cooperative Oncology Group. Am J Clin Oncol 5: 649-655, 1982.

18. de Botton S, Chevret S, Coiteux V, Dombret H, Sanz M, San Miguel J, Caillot D, Vekhoff A, Gardembas M, Stamatoulas A, et al; European APL group: Early onset of chemotherapy can reduce the incidence of ATRA syndrome in newly diagnosed acute promyelocytic leukemia (APL) with low white blood cell counts: Results from APL 93 trial. Leukemia 17: 339-342, 2003.

19. Montesinos P, Bergua JM, Vellenga E, Rayón C, Parody R, de la Serna J, León A, Esteve J, Milone G, Debén G, et al: Differentiation syndrome in patients with acute promyelocytic leukemia treated with all-trans retinoic acid and anthracycline chemotherapy: characteristics, outcome, and prognostic factors. Blood 113: 775-783, 2009.

20. Tallman MS and Manji GA: Don't just stand there, do something: strategies for the prevention of early death in acute promyelocytic leukemia: a commentary. Blood Cells Mol Dis 46: 173-174, 2011. 